\title{
Zip From Zog no Acelera Brasil: analisando os eixos temáticos do livro didático para o ensino de inglês em um programa de aceleração de aprendizagem
}

\author{
Patrícia Helena da Silva Costa \\ Secretaria Municipal de Educação, Esportes e Lazer do Rio de Janeiro \\ patriciahscosta@gmail.com
}

\section{Resumo}

O presente artigo investiga a adequação do livro didático de Inglês Zip From Zog $5 A$ ao Programa Acelera Brasil. Buscando verificar como os temas do mundo infanto juvenil são construídos por esses livros didáticos, este trabalho analisa o conteúdo e a organização deste material didático, mais especificamente o componente Livro do Aluno. Ao investigarmos como os temas do mundo infanto juvenil são construídos pelo material, lançamos nossa atenção para os eixos temáticos presentes nas unidades do volume $5 \mathrm{~A}$. A análise do corpus mostrou que esse livro didático não é organizado tematicamente. Sendo assim, as unidades não trabalham a linguagem em contextos ou situações específicas e, portanto, não há construção de significados por parte do material. Os resultados apontam para a não adequação do livro didático Zip From Zog 5A aos objetivos do Programa Acelera Brasil, acarretando, assim, na demanda por um trabalho contextualizado sociohistoricamente, que pense, antes de tudo, nas necessidades de seu publico alvo e no papel dos que participam desse processo como um todo.

Palavras-chave: análise de adequação, eixos temáticos, livro didático de Inglês Zip From Zog 5A, Programa Acelera Brasil.

\section{Abstract}

This article aims to investigate the suitability of the English coursebook Zip From Zog $5 A$ to the Acelera Brasil Program. In order to observe how the themes of the juvenile world are constructed by this coursebook, this study analyses the content and organization of the coursebook Zip From Zog 5A, especially the Student's Book. With a view to investigate how the themes of the juvenile world are constructed by the coursebook, we focused our attention on the themes of the units in the material. The analysis showed that the coursebook is not thematically structured. In doing so, the units of the material do not work with language in specific contexts or situations. Therefore, there are no meaning constructions in the 
coursebook. The results of this research point that the coursebook Zip From Zog 5A does not suit the Acelera Brasil Program, which shows the demands for a sociohistorically contextualized work that prioritizes its target public's needs and the role of the ones involved in this process.

Keywords: analysis of suitability, themes, English coursebook Zip From Zog 5A, Acelera Brasil Program.

\section{Introdução}

Com a implementação do Programa Rio Criança Global (PRCG), todos os alunos do ensino fundamental da rede pública municipal de educação do Rio de Janeiro passam a ter aulas de Inglês a partir do $1^{\circ}$ ano. Sendo assim, o ensino desta LE passa a ser oferecido a todos os alunos matriculados nas escolas públicas municipais do Rio de Janeiro, inclusive os discentes do Programa Acelera Brasil (LALLI, 2000). Este Programa tem como objetivo corrigir o fluxo escolar de alunos alfabetizados multirrepetentes do $2^{\circ}$ ao $4^{\circ}$ anos do ensino fundamental, com defasagem idade/ano escolar. Nas escolas da rede pública municipal do Rio de Janeiro, o Programa Acelera Brasil é comumente conhecido como Acelera I. Esta nomenclatura é utilizada para diferenciar o Acelera dos outros programas de correção de fluxo realizados pela Secretaria Municipal de Educação do Rio de Janeiro (SME-RJ) ${ }^{1}$. E foi a minha experiência como professora de Inglês de duas turmas de Acelera I, durante o ano de 2012, a grande motivação para a realização desta pesquisa.

Dentre as características do Programa Acelera Brasil, temos a utilização de materiais didáticos elaborados exclusivamente para o seu público alvo. De acordo com Lalli (2000) o conteúdo trabalhado nesses materiais enfatiza temas práticos do cotidiano e de interesse do mundo infanto juvenil, a fim de promover a participação dos alunos em sala de aula, na escola e na comunidade.

Diferentemente deste material específico, temos o livro didático para as aulas de Inglês do Acelera I. Baseados no fato de que os alunos do Acelera I são da mesma faixa etária que os alunos do $5^{\circ}$ ano do ensino

${ }^{1}$ Este era o nome da secretaria em questão, até o momento da elaboração deste artigo. Com a posse do prefeito eleito, em 01 de janeiro de 2017, esta secretaria passou a se chamar Secretaria Municipal de Educação, Esportes e Lazer (SMEEL). 
fundamental, a SME-RJ determina que os livros didáticos Zip From Zog 5A e $5 B$, utilizados com os alunos do $5^{\circ}$ ano do Ensino Fundamental, também sejam empregados nas aulas de Inglês do Acelera I.

Ainda que o PRCG e o Acelera I pertençam a um mesmo contexto, o das escolas públicas municipais do Rio de Janeiro, esses dois projetos possuem origens e propósitos distintos. Diante de tudo o que foi dito até agora sobre os dois projetos, selecionar o livro didático de Inglês com base apenas na igualdade de faixa etária dos alunos não demonstra o mesmo cuidado que percebemos na elaboração do material didático específico para o Acelera I. Neste sentido, em minha dissertação de mestrado ${ }^{2}$, no Programa Interdisciplinar de Pós-Graduação em Linguística Aplicada, na Universidade Federal do Rio de Janeiro, investiguei a adequação dos livros didáticos Zip From Zog 5A e 5B ao Programa Acelera Brasil.

Ao destacarmos as características do Programa Acelera Brasil, chegamos a três aspectos principais, a saber: elaboração de materiais didáticos focados nos alunos, promoção da participação dos alunos na sala de aula, na escola e na comunidade e ênfase em temas práticos do cotidiano e de interesse do mundo infanto juvenil. Desta forma, ao investigarmos a adequação dos livros didáticos Zip From Zog $5 A$ e 5B, identificamos como esses aspectos estão presentes, ou não, nos livros didáticos para o ensino de Inglês no Acelera I. Devido às limitações de tamanho deste artigo, e por entendermos a relevância do eixo temático como o fio condutor das unidades que compõem um livro didático, o recorte aqui dado à minha dissertação se ocupa apenas da análise das seis primeiras páginas da Unidade 1 do volume 5A do livro didático de Inglês, no que diz respeito ao terceiro aspecto mencionado anteriormente, ou seja, dos temas práticos do cotidiano e de interesse do mundo infanto juvenil. Sendo assim, a pergunta de pesquisa que norteia este trabalho é: Como os temas do mundo infanto juvenil são construídos pelo livro didático Zip From Zog 5A?

Pautada por uma teoria de linguagem de base bakhtiniana (BAKHTIN, 1997 [1979]; 2006 [1929]) e sistêmico-funcional (HALLIDAY; HASAN, 1989; HALLIDAY; MATTHIESSEN, 2014) e por uma abordagem crítica de discurso (FAIRCLOUGH, 2001 [1992]; 2003; 2010 [1995]), a análise documental (LÜDKE; ANDRÉ, 2013 [1986]) aqui realizada dedica-se aos eixos temáticos presentes na Unidade 1 no livro

\footnotetext{
${ }^{2}$ Zip From Zog no Acelera Brasil: uma análise de adequação do livro didático para o ensino de inglês em um programa de aceleração de aprendizagem.
} 
didático de Inglês, a fim de investigarmos quais os contextos culturais existentes e como esses mesmos contextos remetem, ou não, ao mundo infanto-juvenil.

\section{Programa Rio Criança Global}

O Programa Rio Criança Global (PRCG), criado pela Prefeitura do Rio através do decreto $n^{\circ} 31187$ de 6 de outubro de $2009^{3}$, por meio da SME-RJ, tem como objetivo intensificar e estender o ensino de Inglês nas escolas da rede pública municipal do Rio de Janeiro.

A implementação do programa iniciou em 2010, com alunos do $1^{\circ}$ ao $3^{\circ}$ ano tendo uma aula semanal, de 50 minuto, do idioma. A partir de então, o PRCG é efetivado da seguinte forma: em 2011 inclui-se o $4^{\circ}$ ano; em 2012 o $5^{\circ}$ ano; em 2013 o $6^{\circ}$ ano e assim sucessivamente, sendo que do $4^{\circ}$ ao $9^{\circ}$ ano os alunos têm dois tempos semanais de Inglês.

Para a implementação do PRCG, a SME-RJ contratou a Cultura Inglesa $\mathrm{S} / \mathrm{A}^{4}$, cuja participação inclui a aplicação da avaliação oral do concurso público para seleção de docentes, o desenvolvimento das "capacitações" dos professores ao longo do ano letivo, a elaboração e venda do material didático. No Ensino Fundamental I, temos o livro didático Zip From Zog, enquanto que no Ensino Fundamental II o livro didático utilizado é o Interaction ED. Ambas coleções foram produzias pela editora LF Educacional, braço do grupo Learning Factory, responsável pela elaboração dos materiais didáticos da Cultura Inglesa.

\section{Programa Acelera Brasil}

Idealizado por João Batista Araújo e Oliveira, secretário executivo do Ministério da Educação (MEC) em 1995, e concebido pelo Centro de

${ }^{3}$ RIO DE JANEIRO. Decreto n. ${ }^{\circ}$ 31.187, de 06 de outubro de 2009. Cria o Programa Rio Criança Global no âmbito da Secretaria Municipal de Educação. Diário Oficial do Município do Rio de Janeiro, Poder Executivo, Ano XXIII, $\mathrm{N}^{\mathrm{o}} 138,07$ de out. de 2009, p. 5.

${ }^{4}$ Curso de Inglês líder de mercado no Rio de Janeiro que possui contrato com a SME-RJ para a terceirização parcial do ensino de Inglês no Ensino Fundamental I nas escolas da rede municipal. 
Ensino Tecnológico de Brasília (CETEB), o Programa de Aceleração de Aprendizagem (PAA) foi elaborado como uma medida para a correção do fluxo escolar.

A fim de disseminar o PAA, temos em 1996 a parceria entre o Instituto Ayrton Senna (IAS) e o CETEB, apoiados pela Petrobrás. Surge, então, o Programa Acelera Brasil. Conforme nos mostra Lalli (2000), o Programa Acelera Brasil tem como objetivo assumir um compromisso, no Estado ou município, de adotar medidas de combate à repetência em massa, através de estratégias adequadas de ensino. A principal estratégia para correção do fluxo reside na implementação de programas de aceleração da aprendizagem, em que alunos alfabetizados multirrepetentes do $2^{\circ}$ ao $4^{\circ}$ anos do ensino fundamental, com defasagem idade/ano escolar, são agrupados em classes com 25 alunos no máximo, com possibilidade de recuperar a auto-estima, assimilar parcelas significativas do programa e serem promovidos para outros níveis escolares, sendo que a meta é que a maioria dos discentes seja encaminhada para o $6^{\circ}$ ano, caso as avaliações demonstrem as condições dos alunos para tal promoção.

O Acelera Brasil utiliza materiais didáticos voltados diretamente para os alunos. Distribuídos em quatro livros ${ }^{5}$, os conteúdos são abordados em projetos, cujos temas escolhidos permitem explorar aspectos relacionados a cada uma das disciplinas básicas, Língua Portuguesa, Matemática, História, Geografia e Ciências, de forma contextualizada e integrada, com oportunidades para aprofundamento ou revisão posterior de conceitos e operações. Baseiam-se nos currículos oficiais e enfatizam temas práticos do cotidiano e de interesse do mundo infanto-juvenil (LALLI, 2000). O material também inclui um conjunto de 40 livros de vários gêneros literários e momentos de avaliação e revisão ao término de cada unidade, chamada Subprojeto.

Nas escolas da rede pública municipal do Rio de Janeiro, o Programa Acelera Brasil é comumente conhecido como Acelera I. Os discentes deste projeto possuem dois tempos de aula de Inglês, de 50 minutos cada, todas as quartas-feiras. Além das aulas de língua estrangeira, esses alunos também são atendidos por professores de Educação Física e Artes, neste mesmo dia da semana. Enquanto a turma está com esses professores, os docentes regentes estão em reunião de planejamento com a

${ }^{5}$ Livro 1: Minha identidade; Livro 2: As criações de cada um; Livro 3: Nossa história, nossa cultura; Livro 4: A Terra que queremos. 
Coordenadora Pedagógica da unidade escolar, ou, quinzenalmente, com o seu respectivo supervisor.

\section{Linguagem: uma prática sócio, histórica e culturamente situada}

Ao destacar a natureza social da linguagem Bakhtin (2006 [1929]) afirma que todas as esferas da atividade humana são caracterizadas pela utilização da linguagem em forma de enunciados, orais e escritos, essenciais para a comunicação verbal entre os indivíduos.

É por meio dos enunciados que emanam das esferas da atividade humana que se dá o contato entre a linguagem e a realidade. Ao mesmo tempo em que a linguagem se insere na vida através dos enunciados que a realizam, a vida se insere na linguagem por conta, também, dos enunciados.

Bakhtin (1997 [1979]) ressalta o papel da interação social no processo de desenvolvimento humano. Desta forma, o progresso da experiência verbal individual do homem ocorre na interação contínua e permanente com os enunciados individuais do outro. Ao interagirmos com a fala dos outros, isto é, com os enunciados dos outros, provocamos transformações, de maneira que a assimilamos, a reestruturamos. As nossa palavras são, então, formadas pelas palavras dos outros.

Um enunciado concreto é um elo na cadeia da comunicação verbal de uma dada esfera. As fronteiras desse enunciado determinam-se pela alternância dos sujeitos falantes. Os enunciados não são indiferentes uns aos outros nem são autossuficientes; conhecem-se uns aos outros, refletem-se mutuamente. São precisamente esses reflexos reciprocos que lhes determinam o caráter. $O$ enunciado está repleto dos ecos $e$ lembranças de outros enunciados, aos quais está vinculado no interior de uma esfera comum da comunicação verbal. $O$ enunciado deve ser considerado acima de tudo como uma resposta a enunciados anteriores dentro de uma dada esfera. (BAKHTIN, 1997 [1979], p. 316)

Ao valorizar a enunciação, Bakhtin (2006 [1929]) expõe a indissolúvel ligação desta com as condições da comunicação, que, por sua vez, estão intimamente relacionadas às esferas socais. De igual importância para a nossa pesquisa, e em consonância com as visão de 
discurso e linguagem adotadas, propomos a teorização da Linguística Sistêmico-Funcional, doravante LSF, (HALLIDAY; HASAN, 1989; HALLIDAY; MATTHIESSEN, 2014) como embasamento para a análise proposta neste trabalho.

Halliday e Hasan (1989) apontam para o fato de que a LSF está particularmente envolvida com as relações entre linguagem e estrutura social, sendo linguagem, especificamente a linguagem verbal, entendida como um dos vários sistemas de construção de significado que constituem a cultura humana. Podemos dizer, então, que a LSF objetiva relacionar a linguagem a um aspecto da experiência humana em particular: o social.

Dentro da perspectiva da LSF, todo texto, isto é,"qualquer instância de linguagem, em qualquer meio, que faça sentido para alguém que conhece a linguagem" (HALLIDAY; MATTHIESSEN, 2014, p.3) ${ }^{6}$, ocorre em dois contextos, simultaneamente: o contexto de cultura e o de situação. Halliday e Matthiessen (2014, p.33) ${ }^{7}$, definem o contexto de cultura como o potencial contextual de uma comunidade, isto é, "o que os membros de uma comunidade podem significar em termos culturais; (...) - como um ambiente de significados no qual vários sistemas semióticos operam, incluindo a linguagem, a paralinguagem (...)". Já o contexto de situação configura-se como um contexto de produção mais imediato. Trata-se de um contexto que pode ser entendido como o ambiente do texto (HALLIDAY; HASAN, 1989), incluindo o ambiente verbal e a situação na qual o texto foi proferido.

Retomando aqui a principal preocupação da LSF, que são as relações entre a linguagem e a estrutura social, podemos atentar para o fato de que dentro de uma perspectiva sistêmico-funcional nós usamos a linguagem para construir a nossas experiências e para desenvolver as nossas interações com outras pessoas. No que diz respeito à construção da experiência humana, usamos a linguagem para representar e construir nossas vivências no mundo e nossa realidade, ou seja, para codificar significados da nossa experiência. Temos então, a metafunção ideacional (HALLIDAY; MATTHIESSEN, 2014). Além de construir nossas experiências, a

6 "any instance of language, in any medium, that makes sense to someone who knows the language" (HALLIDAY; MATTHIESSEN, 2014, p.3)

7 "what the members of a community can mean in cultural terms; (...) as an environment of meanings in which various semiotic systems operate, including language, paralanguage (...)" (HALLIDAY; MATTHIESSEN, 2014, p.33) 
linguagem também atua nas nossas relações pessoais e sociais com outros indivíduos. Halliday e Matthiessen (2014) denominam esta metafunção como interpessoal. Apesar destas duas metafunções poderem ser amplamente combinadas, sem que uma restrinja a outra, faz-se necessário que os significados ideacionais e interpessoais sejam organizados dentro do texto de maneira linear e coerente, por meio da metafunção textual (HALLIDAY; MATTHIESSEN, 2014).

Tanto Bakhtin (1997 [1979]; 2006 [1929]) quanto Halliday (HALLIDAY; HASAN, 1989; HALLIDAY; MATHIESSEN, 2014) concebem a linguagem como uma prática sócio, histórica e culturalmente situada. Retomando alguns pressupostos bakhtinianos, todas as esferas da atividade humana estão impregnadas pelo uso da linguagem. Inúmeras e diversas práticas sociais resultam em inúmeros e diversos modos de utilização da língua, configurando-se, assim, o que Bakhtin (1997 [1979], p. 280) define por gêneros do discurso, ou seja, "tipos relativamente estáveis de enunciados (orais e escritos), concretos e únicos, que emanam dos integrantes duma ou doutra esfera da atividade humana."

Dada a importância dos enunciados, isto é, dos gêneros do discurso, para todas as esferas da atividade humana, Bakhtin (1997 [1979], p. 282) afirma que "ignorar a natureza do enunciado e as particularidades de gênero que assinalam a variedade do discurso em qualquer área do estudo linguístico leva ao formalismo e à abstração, desvirtua a historicidade do estudo, enfraquece o vínculo existente entre a língua e a vida."

Desta forma, Bakhtin (1997 [1979]) discorre a respeito dos elementos constitutivos do gênero, a saber: o tema, a forma composicional e o estilo. O primeiro elemento configura-se como a realidade em que se dá o enunciado, que engloba os sentidos vinculados ao uso da linguagem em situações e contextos específicos. O segundo elemento, a forma composicional, diz respeito ao modo de organização do gênero, ao "tipo de estruturação e de conclusão de um todo, tipo de relação entre o locutor e os outros parceiros da comunicação verbal (relação com o ouvinte, ou com o leitor, com o interlocutor, com o discurso do outro, etc.) (BAKHTIN, 1997 [1979], p. 284). Já o estilo, terceiro elemento constitutivo, pode ser definido como a seleção dos recursos lexicais e gramaticais da língua.

Além de compartilharem a mesma concepção de linguagem, Bakhtin (1997 [1979]; 2006 [1929]) e Halliday (HALLIDAY; HASAN, 1989; HALLIDAY; MATTHIESSEN, 2014), também apresentam outras 
possibilidades de diálogo, especificamente no que diz respeito às metafunções da linguagem e aos elementos constitutivos do gênero discursivo. Recapitulando o conceito de metafunção ideacional, podemos dizer que ela está refletida na forma como a linguagem representa e constrói a realidade à nossa volta. Assim, a linguagem é o meio pelo qual codificamos os significados da nossa experiência. De maneira semelhante, o conceito de tema bakhtiniano também abarca a realidade que constitui a experiência humana, ao dar conta do momento sociohistórico no qual o gênero é realizado.

Ao retomarmos a metafunção interpessoal, vemos pontos em comum com o conceito de forma composicional. Ao dizermos que este elemento constitutivo do gênero organiza a estrutura do mesmo, atuando nos tipos de relação entre os parceiros da comunicação verbal, podemos relacioná-lo com a organização das nossas relações pessoais e sociais com outros indivíduos, expressa pela linguagem através da metafunção interpessoal.

Por fim, os significados ideacionais e interpessoais são estruturados linguística e formalmente dentro do texto, por meio da metafunção textual. Essa materialização da informação também está presente no conceito de estilo bakhtiniano, uma vez que este elemento constitutivo do gênero abarca as escolhas lexicogramaticais presentes no momento da enunciação.

Cabe apontar aqui que as metafunções da linguagem foram elaboradas por Halliday com o objetivo de descrever e entender a gramática da língua inglesa (HALLIDAY; MATTHIESSEN, 2014). Entretanto, este não é nosso propósito. Ainda assim, acreditamos que suas reflexões sejam de extrema importância para a análise de material didático que nos propomos a fazer, visto que nos afiliamos à sua visão de "atividade humana concebida como prática social situada" e à sua compreensão da relação entre a linguagem e a estrutura social (TILIO; ROCHA, 2009, p. 303).

Conforme explicado anteriormente, os construtos teóricos elaborados por Halliday atuam na descrição e compreensão da gramática da língua inglesa, diferenciando-se, assim, do nosso objetivo mais amplo, isto é, a análise de adequação do livros didático de Inglês Zip From Zog $5 \mathrm{~A}$ ao Programa Acelera Brasil. Contudo, a opção pelos conceitos da LSF se justificam por estes corroborarem a importância da relação entre a linguagem e a estrutura social, aspecto importante quando se pretende analisar o discurso do/no material didático em questão. 


\section{Análise Crítica do Discurso}

Ao analisarmos o discurso de e em livros didáticos, como é o caso da dissertação que originou este artigo, faz-se necessário definirmos o que entendemos por discurso. Sendo assim, o conceito de discurso utilizado aqui é o mesmo adotado por Fairclough (2001 [1992]), em que o discurso é visto como uma prática social.

Dentro desta perspectiva, Resende \& Ramalho (2006) afirmam que entender o uso da linguagem como prática social acarreta concebê-lo como um agir situado historicamente, que tanto é moldado socialmente como também é responsável pela formação de identidades e relações sociais e sistemas de conhecimento e crença. Ressalta-se, portanto, a relação interna e dialética entre linguagem e sociedade.

A fim de conduzir a análise de livros didáticos proposta neste artigo, adotaremos, além dos fundamentos teóricos da LSF e da concepção bakhtiniana de linguagem, os pressupostos teóricos da Análise Crítica do Discurso (ACD) (FAIRCLOUGH, 2001 [1992]; 2003; 2010 [1995]).

Fairclough (2003) aborda a análise de discurso com base na visão de que a linguagem é uma parte irredutível da vida social. Isto significa que uma forma produtiva de se fazer pesquisa social é por meio do foco na linguagem, utilizando algum tipo de análise de discurso. A ênfase na linguagem, de acordo com Fairclough (2003, p. 5) ${ }^{8}$, não se trata de condensar tudo ao discurso, pois conforme o autor, "trata-se de uma estratégia analítica entre muitas outras, e geralmente faz sentido utilizar a análise do discurso em conjunto com outras formas de análise, como por exemplo, etnografia ou formas de análise institucional."

Ainda assim, Fairclough (2003) defende a ideia de que qualquer análise textual que almeje ser significante em termos sociais deve se conectar com aspectos teóricos sobre o discurso. Da mesma forma, nenhuma compreensão real dos efeitos sociais do discurso é possível sem um olhar atento àquilo que acontece quando as pessoas falam os escrevem.

Ao utilizarmos os principais pressupostos teóricos da ACD, situamos a análise do livro didático de Inglês Zip From Zog 5A como uma

\footnotetext{
8 "it's one analytical strategy amongst many, and it often makes sense to use discourse analysis in conjunction with other forms of analysis, for instance ethnography or forms of institutional analysis" (FAIRCLOUGH, 2003, p. 5)
} 
análise textual que considera o envolvimento do texto em práticas discursivas e sociais de naturezas diversas.

\section{Percurso metodológico}

A análise do livro didático Zip From Zog $5 \mathrm{~A}$ proposta neste estudo caracteriza-se como uma pesquisa qualitativa denominada análise documental (LÜDKE; ANDRÉ, 2013 [1986]) . Este tipo de pesquisa justifica-se pelo fato de entendermos que o livro didático de ensino de Inglês que compõe o corpus deste trabalho configura-se como um documento de fonte primária, isto é, um material impresso que não recebeu nenhum tratamento científico (SÁ-SILVA et al, 2009).

Além da natureza primária do corpus desta pesquisa, outro aspecto que justifica a análise documental é aquele em que a linguagem do documento é fundamental para a investigação. (LÜDKE; ANDRÉ, 2013 [1986]). Neste sentido, estudaremos o problema com base na própria produção escrita das autoras do livro didático.

Uma vez entendido no que consiste a análise documental, faz-se necessário abordarmos a metodologia geralmente utilizada na análise propriamente dita dos dados: a análise de conteúdo. Krippendorff (1980, p. 21, apud, LÜDKE; ANDRÉ, 2013 [1986], p. 48) a define como "uma técnica de pesquisa para fazer inferências válidas e replicáveis dos dados para o seu contexto". É pela descrição e interpretação das mensagens do documento que o pesquisador busca as respostas aos problemas que motivaram a pesquisa.

Outra abordagem teórico-metodológica que pode conduzir a pesquisa documental é a análise de discurso (GILL, 2010), nome empregado a uma diversidade de enfoques no estudo de textos, elaborada com base em diferentes teorias e diferentes tratamentos em diversas disciplinas.

O tópico da análise de discurso é o próprio discurso, entendido aqui como "o uso de linguagem com forma de prática social e não como atividade puramente individual ou reflexo de variáveis situacionais" (FAIRCLOUGH, 2001 [1992], p. 90). Sendo assim, os textos não são vistos de forma essencializada, como se fossem um caminho para se chegar a uma verdade ocultada pelo discurso, mas sim de maneira sócio, histórica e culturalmente contextualizada. 
No que diz respeito ao corpus de análise, a série didática Zip From Zog possui este nome em virtude do personagem Zip. Trata-se de um extraterrestre que veio do planeta Zog com o intuito de ajudar as crianças do PRCG a aprender o idioma em questão. A série teria sido supostamente desenvolvida para os alunos do primeiro segmento do Ensino Fundamental, ou seja, do $1^{\circ}$ ao $5^{\circ}$ ano, e por isso o material é composto pelos livros $1 A$ ao $5 A$ e $1 B$ ao $5 B$, onde $A$ está destinado para o primeiro semestre e $B$ para o segundo.

O material em questão faz parte da coletânea desenvolvida pela editora LF Educacional, responsável pelo desenvolvimento de materiais didáticos para o setor público, da Educação Infantil ao Ensino Médio, integrante da Learning Factory, editora que responde pelo desenvolvimento e comercialização do material didático da Cultura Inglesa.

O volume a ser analisado será o Zip From Zog 5A, pensado para o $5^{\circ}$ ano do ensino fundamental e selecionado para os alunos do Programa Acelera Brasil. No volume 1A o extraterrestre Zip chega ao planeta Terra para auxiliar no ensino de Inglês. No $5 A$, os personagens do livro, acompanhados de Zip, vão para um intercâmbio em Zog. Sendo assim, os volumes 5A e 5B são ambientados no período em que estes personagens estão no planeta extraterrestre.

Além da divisão em dois volumes, o material utilizado pelos alunos é composto pelo Livro do aluno e pelo Play \& Learn ${ }^{9}$. O Livro do Aluno, objeto de nosso estudo e material mais utilizado em sala de aula, contém quatro unidades, sendo estas formadas por quatro lições, desdobradas em duas páginas cada uma. Integrando este kit, e apenas para uso dos docentes, temos o Manual do Professor, que também será acrescentado à análise, já que este componente contextualiza a elaboração do livro didático, um DVD com vídeos e atividades sobre os personagens da coleção e um CD com os áudios das tarefas do Livro do Aluno.

Por se tratar de uma análise documental, o instrumento utilizado no processo de geração de dados consiste na própria seleção do material didático que compõe o corpus de pesquisa. Desta forma, os dados foram gerados a partir do conteúdo e da organização do livro didático Zip From Zog 5A. Mais especificamente, direcionamos a nossa análise às unidades do

9 Material complementar elaborado como atividades digitais e impressas que podem ser utilizadas em conjunto com um CD-ROM que acompanha o kit do professor. 
Livro do Aluno. De igual importância para a análise documental aqui proposta são as informações trazidas pelo Manual do Professor.

Para que possamos cumprir com o objetivo traçado para este artigo, ou seja, compreender como os temas do mundo infanto-juvenil são construídos pelo livro didático Zip From Zog 5A, a categoria de análise a ser empregada origina-se da proximidade conceitual entre a metafunção ideacional hallidiana e a noção bakhtiniana de tema, permitindo-nos, assim, uma análise que contempla a materialidade linguística do livro didático e a relação entre o texto e o contexto social. A categoria de análise a qual nos referimos é a dimensão ideacional-temática, que abrange a forma como os conteúdos do livro didático são ou não situados no mundo (TILIO; ROCHA, 2009). Esta dimensão relaciona-se com os contextos culturais existentes no livro didático e o modo como eles se reportam à realidade e experiência de mundo dos alunos (TILIO, 2013).

\section{0 mundo infanto juvenil no eixos temáticos}

A fim de situarmos a elaboração do livro didático Zip From Zog 5A, traremos agora algumas palavras da Introdução do Manual do Professor. Como nesta seção concentramo-nos nos eixos temáticos presentes no Livro do Aluno, abordamos apenas os trechos da Introdução que de alguma forma remetam à dimensão ideacional-temática. Sendo assim, na Introdução do Manual do livro didático 5A, na parte destinada a Descrição da série, temos:

ZIP from ZOG (...) promove o ensino da língua inglesa de forma lúdica e objetiva, priorizando a produção oral em atividades apropriadas à faixa etária a que se destina (...).

ZIP from ZOG também incorpora temas transversais em suas unidades como ética, saúde e meio ambiente (...). ZIP from ZOG procura trazer estas questões para a sala de aula através de situações simples do dia a dia do aluno. (PARRADO; SANTOS, 2012b, p. IV)

Este trecho do Manual do Professor diz que o volume $5 A$ se preocupa com a dimensão ideacional-temática. Ao incorporarem os temas 
transversais ao ensino de Inglês através de situações simples do cotidiano dos alunos, este volume parece promover um ensino de Inglês situado sociohistoricamente.

Em outra seção da Introdução, denominada Abordagem, também temos a menção a um ensino de Inglês engajado com o contextual cultural dos alunos, o que se configura como uma possibilidade de trabalhar a linguagem situada discursivamente. Neste sentido, Zip From Zog faz "referência a elementos da cultura do aluno (autores nacionais, animais silvestres, paisagens do Rio, etc), e de culturas internacionais" (PARRADO; SANTOS, 2012b, p. IV). Cabe relembrar aqui que quando falamos em contexto cultural estamos nos referindo ao potencial contextual das práticas sociais nas quais os alunos podem estar inseridos, ou seja, estamos nos referindo ao "o que os membros de uma comunidade podem significar em termos culturais (...)" (HALLIDAY; MATTHIESSEN, 2014, p. 32). No que diz respeito à visão do Manual do Professor sobre "a cultura do aluno", podemos dizer que ela se limita a mencionar personalidades brasileiras, fauna e paisagens locais, o que pode acarretar em um entendimento equivocado do que seria trabalhar a linguagem de forma significativa e contextualizada.

No que diz respeito aos Componentes da série, "O Livro do Aluno (LA) é dividido em unidades, que são organizadas tematicamente, com tópicos de interesse do aluno, e que permitem a exploração dos temas transversais" (PARRADO; SANTOS, 2012b, p. IV). Conforme podemos observar, assim como o Programa Acelera Brasil diz focar em temas práticos do cotidiano e de interesse do mundo infanto juvenil, o livro didático Zip From Zog $5 A$ também parece se preocupar com o contexto cultural dos alunos. Entretanto, faz-se necessário problematizar o que o Manual chama de tema e o que ocorre realmente nas unidades do Livro do Aluno 5A.

Primeiramente, precisamos esclarecer que a nossa visão de tema dialoga com o conceito bakhtiniano, uma vez que compreendemos tema como a realidade em que se dá o enunciado (BAKHTIN, 1997 [1979]). Para o autor, todo enunciado, ou seja, toda manifestação verbal, ocorre em uma determinada realidade, que por sua vez engloba os sentidos veiculados ao uso da linguagem em situações e contextos específicos.

Desta forma, quando o Manual do Professor diz que as unidades são organizadas tematicamente, espera-se que os conteúdos trazidos por elas estejam situados no mundo, em um determinado momento 
sociohistórico (TILIO; ROCHA, 2009). Cabe-nos, a partir de agora, analisar como essa preocupação com a dimensão ideacional-temática se apresenta, ou não, ao longo das unidades do livro.

Ao mostrar os conteúdos de cada unidade (Fig. 1), o Livro do Aluno utiliza figuras para ilustrar o que o Manual nos apresenta como o tema de cada unidade. Sendo assim, no volume $5 A$, na primeira unidade, cujo suposto tema é Things we wear (Coisas que usamos), temos uma mala com algumas peças de roupas; na segunda unidade, What's the weather like? (Como está o tempo?), temos a figura de um dia nublado; na terceira unidade cujo suposto tema é What a busy week! (Que semana ocupada!), temos um relógio digital marcando seis horas da manhã e logo abaixo os dias da semana, como se fosse um calendário; na quarta unidade, A new world (Um novo mundo), temos uma figura que representa o planeta $\mathrm{Zog}$.

Figura 1: Tabela de conteúdos Zip From Zog 5A
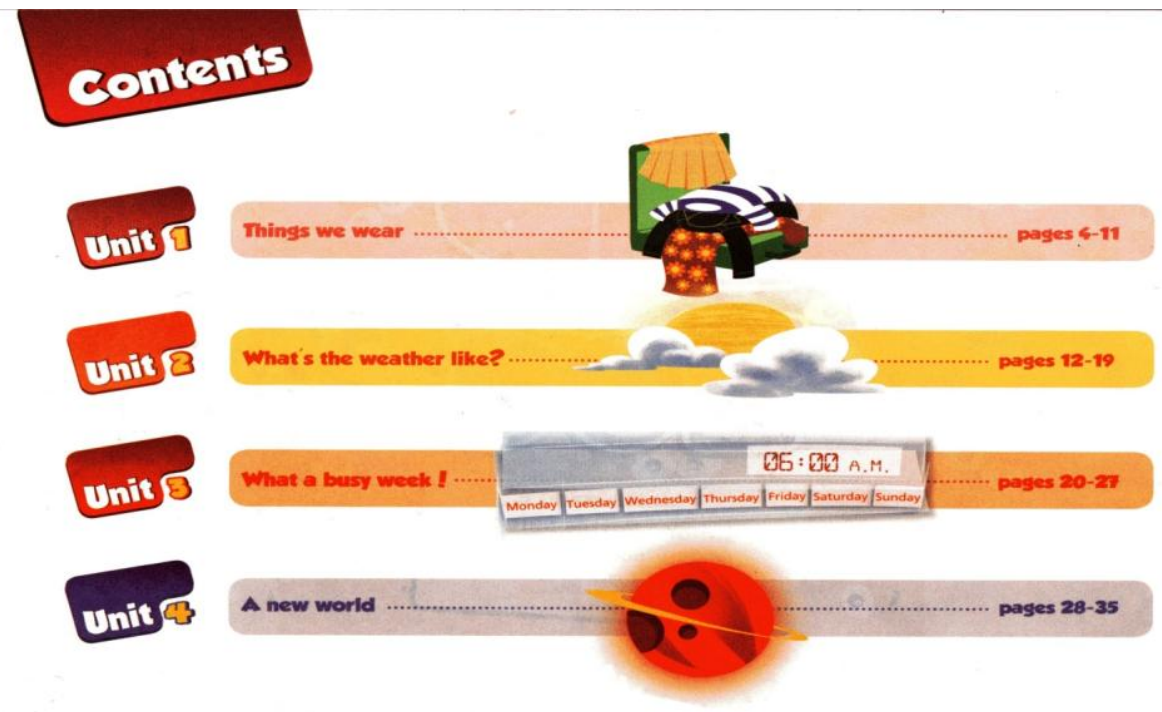

Fonte: Parrado e Santos (2012a, p.2)

Logo no início da Lição 1 da Unidade 1, os alunos são apresentados aos personagens do livro que irão para Zog, conforme nos mostra a Fig. 2 (Next destination Zog!). De acordo com o Manual do Professor (p. 6): "Nos 
livros 5A e 5B, os personagens do livro farão um intercâmbio cultural em Zog, onde aprenderão sobre aspectos culturais, costumes e valores diferentes dos seus." Sendo assim, além de ser "dividido em unidades, que são organizadas tematicamente", os livros didáticos $5 A$ e $5 B$ também são ambientados durante o período em que seus personagens participam deste intercâmbio.

Figura 2: Apresentação à Unidade 1

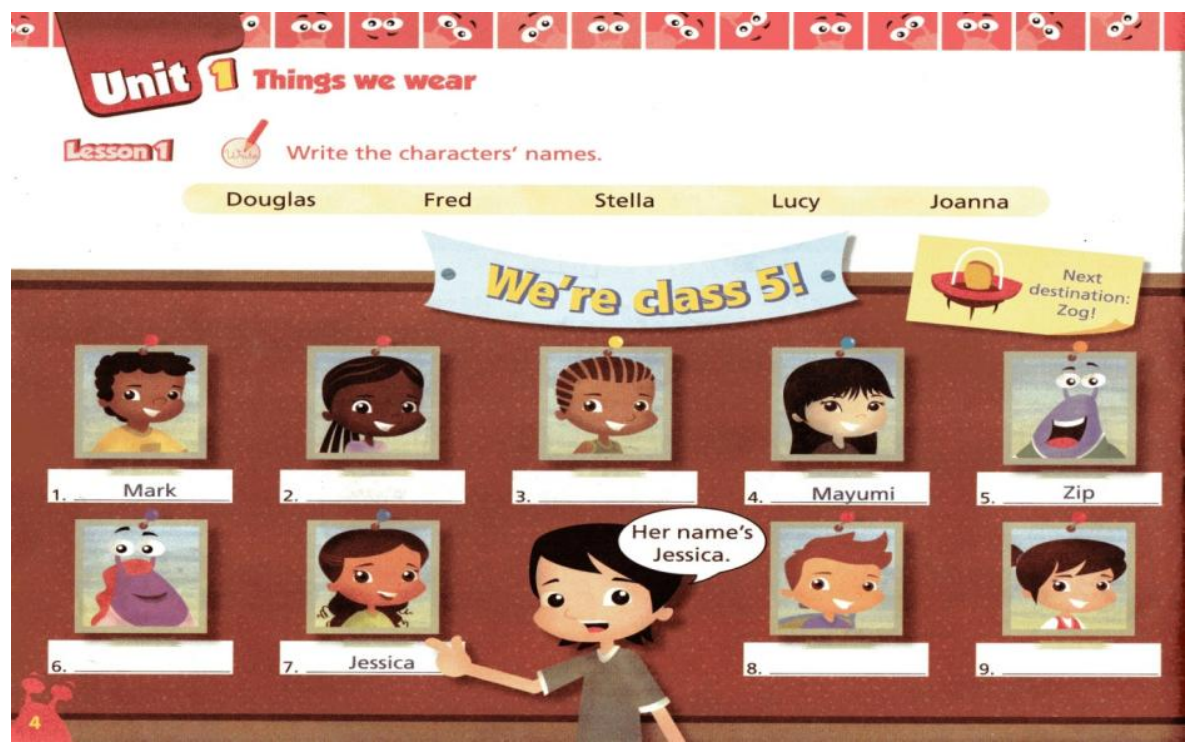

Fonte: Parrado e Santos (2012a, p.4)

Entretanto, o que a princípio se configura como conteúdo situado no mundo, acaba por se desenvolver como uma prática de linguagem em um vácuo social, ou seja, como uma prática de linguagem que não dialoga com os contextos culturais dos alunos.

$\mathrm{O}$ intercâmbio para o planeta $\mathrm{Zog}$, ao contrário do que afirma o Manual do Professor, não é trabalhado como uma situação que faça parte do dia a dia do aluno. Acreditamos que a menção a este tipo de evento justifica-se pelo fato das autoras do material didático integrarem um contexto social no qual os alunos realmente fazem intercâmbio entre o Brasil e países de fala inglesa.

O que vemos na primeira unidade (Things we wear) é a ênfase dada 
ao vocabulário referente a roupas e acessórios (Fig.3) e também à diferença entre itens no plural e no singular (Fig.4). Como podemos observar através da Fig. 3, a personagem Lucy se encontra em seu quarto arrumando as malas para a sua viagem de intercâmbio. Entretanto, ocorre que a mala da personagem está dividida em itens no singular e no plural (Fig.4), situação esta que nos parece bem distante do cotidiano dos alunos, já que ninguém arruma a mala preocupado(a) em colocar de um lado os itens no singular e no outro os no plural.

Figura 3: Vocabulário referente a roupas e acessórios

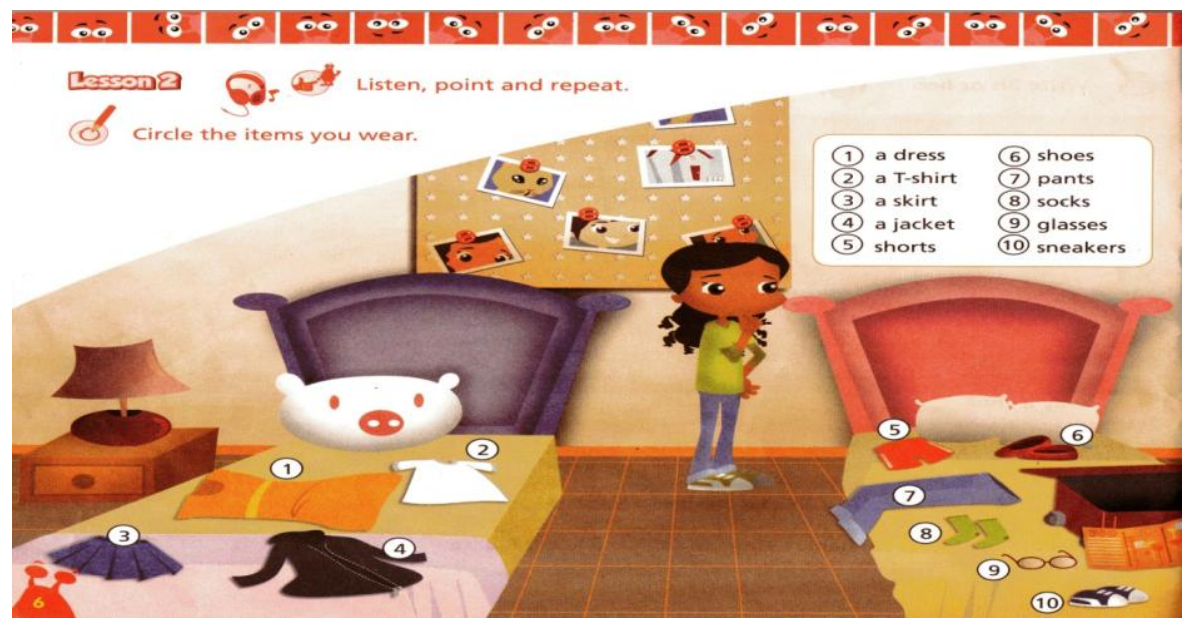

Fonte: Parrado e Santos (2012a, p.6)

Outro aspecto que nos faz questionar a preocupação do material didático em situar o ensino do Inglês em um momento sociohistórico é a presença do mascote Olympio ao final da página 7, na Lição 2 da Unidade 1, como também podemos observar pela Fig. 4. Este mascote sinaliza o momento em que o professor pode abordar as olimpíadas e os esportes olímpicos. Contudo, sua presença é mais uma forma de mostrar que a preocupação com a dimensão ideacional-temática que, aparentemente, localizamos no Manual do Professor não se aplica às lições do Livro do Aluno. Não há relação entre o intercâmbio para Zog, a unidade Things we wear e a ilustração do mascote jogando basquete. 
Figura 4: Mala dividida em itens no singular e plural

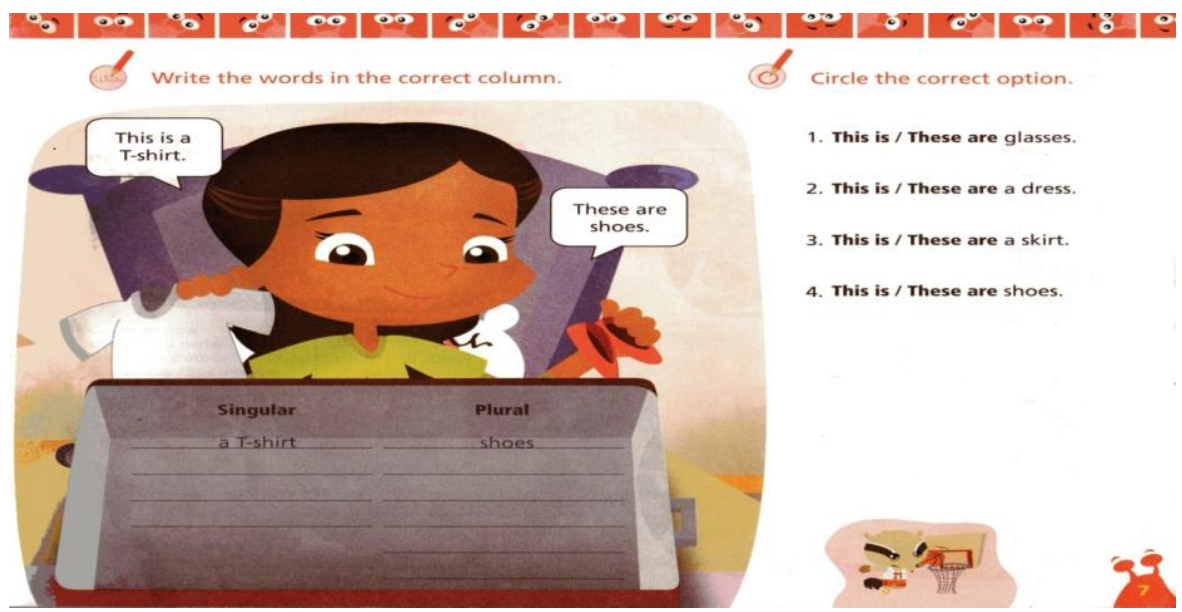

Fonte: Parrado e Santos (2012a, p.7)

Já na Lição 3 da primeira unidade, o volume $5 A$ traz uma situação com a qual os alunos podem se identificar. A Fig. 5 nos traz uma história envolvendo um outro personagem do livro, um menino chamado Fred, que na companhia de sua mãe e de seu irmão mais novo, também está arrumando suas malas para a viagem à Zog. Ao recolher as roupas de Fred de uma pilha de roupas no chão do quarto do menino, a mãe encontra uma camisa suja e pergunta a Fred se a mesma pertence a ele. O menino tenta enganá-la e culpa o irmão mais novo, mas acaba admitindo que a camisa suja é dele. 
Figura 5: História envolvendo o personagem Fred

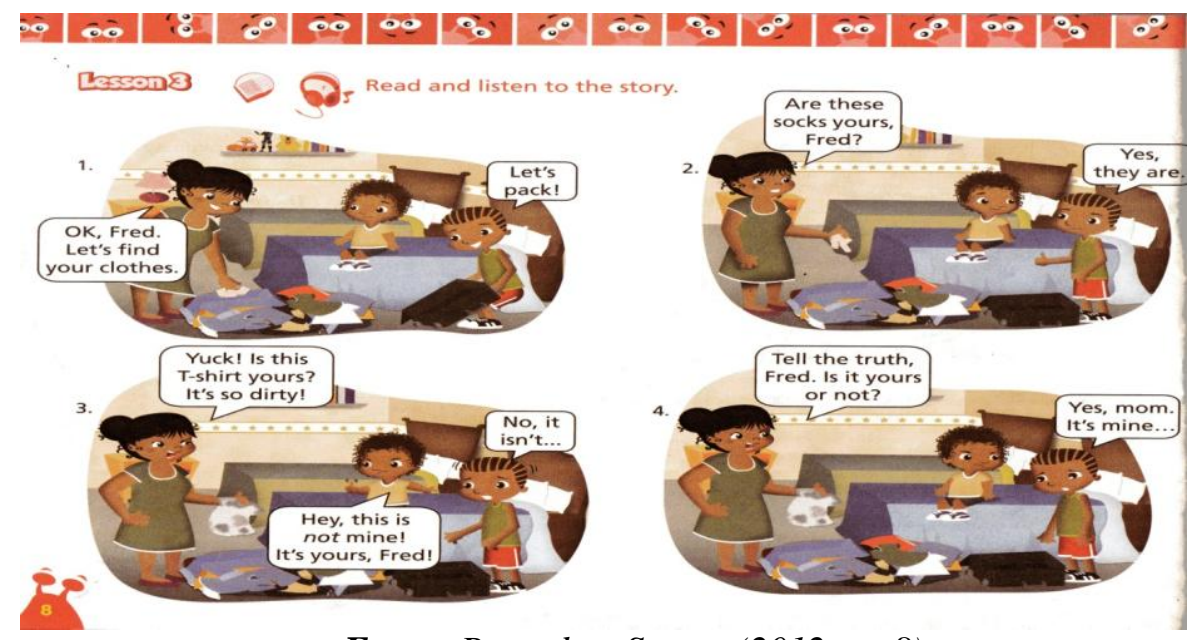

Fonte: Parrado e Santos (2012a, p.8)

Esta história, diferentemente da situação representada pela personagem Lucy, é um momento onde o conteúdo da Unidade 1 é posicionado em um tempo e espaço específicos, podendo dialogar com o cotidiano dos alunos. A situação vivida pelo menino Fred, além de permitir o trabalho com o tema transversal ética, conforme sugere o Manual do Professor, é também uma forma de abordar a linguagem, contextualizandoa sociohistoricamente. Infelizmente, este direcionamento não esta presente na continuação da Lição 3, na página 9, (Fig.6), uma vez que o Livro do Aluno $5 A$ retoma o foco na lexicogramatica.

Diante dos aspectos levantados até aqui, podemos dizer que não há um eixo temático que efetivamente conduza a Unidade 1. O que o Manual do Professor denomina como tema, Things we wear, trata-se, na verdade, do título dado à primeira unidade, título este que apenas sinaliza quais conteúdos estruturais são trabalhados na unidade. Neste sentido, ao invés de trazer conteúdos situados no mundo, a Unidade 1 nos apresenta o uso da linguagem em um vácuo social. 
Figura 6: Atividades que retomam o foco na lexicogramática

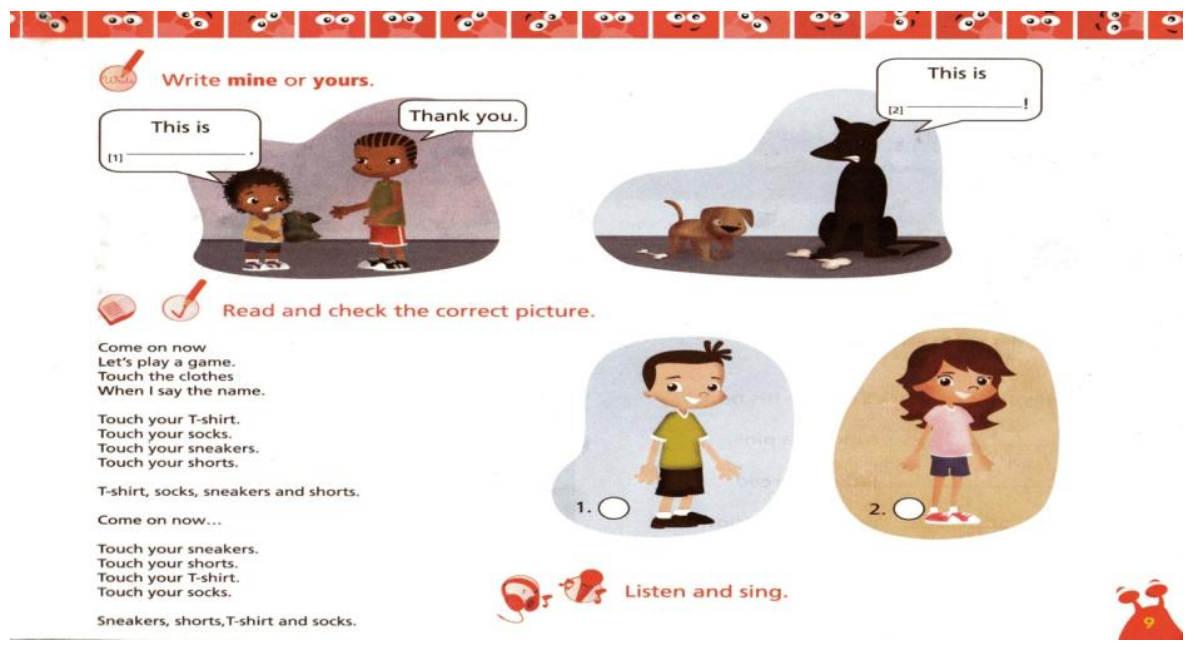

Fonte: Parrado e Santos (2012a, p.9)

A postura adotada na Unidade 1 é repetida nas demais unidades do material ao longo do livro didático Zip From Zog 5A. Portanto, quando o Manual do Professor diz que as unidades são organizadas tematicamente, o que temos são títulos, nomenclaturas cuja função é delimitar o que será trabalhado lexicogramaticalmente. Isso significa que na Unidade 2, What's the weather like?, unidade na qual os personagens já estão no planeta Zog, o conteúdo enfatizado é o vocabulário referente aos diferentes tipos de clima e estações do ano e também algumas peças de vestuário apropriadas para determinadas condições climáticas; na Unidade 3, What a busy week!, o foco está nos dias da semana e em atividades que podem ser realizadas no dia a dia (em casa ou na escola); e na Unidade 4, A new world; o conteúdo enfocado destina-se a trabalhar vocabulário e expressões utilizadas para descrever lugares e ações, sempre relacionados com paisagens e atividades do planeta Zog. O Quadro 1 nos mostra a inexistência de temas na organização das unidades do livro didático 5A, uma vez que essas unidades são conduzidas pelos aspectos lexicogramaticais sinalizados pelos seus respectivos títulos. 
Quadro 1: Organização das unidades do Zip From Zog 5A

\begin{tabular}{|c|c|c|c|}
\hline Unidades & Temas & Títulos & Aspectos lexicogramaticais \\
\hline Unidade 1 & - & Things we wear & $\begin{array}{c}\text { vocabulário referente a roupas e } \\
\text { acessórios; diferença entre itens } \\
\text { no plural e no singular }\end{array}$ \\
\hline Unidade 2 & - & $\begin{array}{c}\text { What's the } \\
\text { weather like? }\end{array}$ & $\begin{array}{c}\text { vocabulário referente aos } \\
\text { diferentes tipos de clima e } \\
\text { estações do ano; peças de } \\
\text { vestuário apropriadas para } \\
\text { determinadas condições } \\
\text { climáticas }\end{array}$ \\
\hline Unidade 3 & - & What a busy & $\begin{array}{c}\text { dias da semana e atividades que } \\
\text { podem ser realizadas no dia a dia } \\
\text { (em casa ou na escola) }\end{array}$ \\
\hline Unidade 4 & - & A new world & $\begin{array}{c}\text { vocabulário e expressões } \\
\text { utilizadas para descrever lugares } \\
\text { e ações, sempre relacionados } \\
\text { com paisagens e atividades do } \\
\text { planeta Zog }\end{array}$ \\
\hline
\end{tabular}

Fonte: Costa (2015)

\section{Considerações finais}

Conforme pontuado na introdução deste trabalho, as limitações de espaço estabelecidas para este artigo nos permitiram apresentar a análise das seis primeiras páginas da Unidade 1 do livro didático Zip From Zog $5 \mathrm{~A}^{10}$. Considerando o fato de que as características trazidas nessas primeiras páginas se repetem ao longo do material didático, podemos dizer que o livro não é organizado tematicamente, com base no nosso entendimento de tema. O que o Manual do Professor chama de tema é, na verdade, um nome, um título dado à unidade. Esta nomenclatura, conforme observamos, possui o propósito de introduzir o conteúdo estrutural que será abordado. Sendo assim, as unidades do livro não trabalham a linguagem em contextos ou situações específicas e, portanto, não há construção de significados por parte do material. Ao ambientar o livro em um contexto

${ }^{10}$ A análise das demais unidades do volume $5 A$ e das unidades existentes no volume $5 B$ encontram-se em minha dissertação de mestrado. 


\section{Zip From Zog no Acelera Brasil...}

cultural fictício, como é o caso do extraterrestre Zip e seu planeta Zog, o livro didático Zip From Zog $5 A$ não estabelece um vínculo com o mundo infanto juvenil que cerca os alunos e, desta forma, não remete ao cotidiano dos discentes e às suas experiências de vida.

Com base no presente estudo, no que diz respeito aos temas do mundo infanto juvenil, podemos dizer que o material didático selecionado para as aulas de Inglês do Acelera I não se adequa aos objetivos deste Programa do Acelera Brasil. A escolha, feita pela SME-RJ, de um material que foi supostamente elaborado para os alunos do $5^{\circ}$ ano regular do Ensino Fundamental foi feita apenas com base na equivalência de idade entre os alunos deste nível de ensino e os discentes do Acelera I, deixando de lado, assim, reflexões em torno das discrepâncias entre o material didático de Inglês pensado para o PRCG e este programa de aceleração.

Se pensarmos a respeito dos participantes envolvidos no evento discursivo sala de aula, ou seja, os alunos, professores e o livro didático em si, veremos que é possível incluirmos aqui a SME-RJ, devido ao seu papel decisivo na escolha do livro didático de Inglês.

A análise de adequação que realizamos aponta para a necessidade de elaboração de material didático de Inglês que englobe o conteúdo trabalhado pelo material desenvolvido especialmente para os alunos do Acelera Brasil. É importante salientar aqui que não pretendemos que os livros didáticos Zip From Zog $5 A$ e $5 B$ sejam banidos das salas de aula do Acelera I. O que queremos dizer é que assim como há a possibilidade de os professores de Inglês adaptarem as atividades do material da LF Educacional, também existe a possibilidade de se elaborar materiais de Inglês pensando para os alunos do Acelera I e que integre conteúdo trabalhado pelos professores regentes.

\section{Referências}

BAKHTIN, Mikhail. M. [1979]. Estética da criação verbal. São Paulo: Martins Fontes, 1997.

BAKHTIN, Mikhail. M. [1929] Marximismo e filosofia da linguagem. São Paulo: Hucitec, 2006.

COSTA, Patrícia. H. S. Zip From Zog no Acelera Brasil: uma análise de 
adequação do livro didático para o ensino de inglês em um programa de aceleração de aprendizagem. 2015.168 f. Dissertação (Mestrado em Linguística Aplicada) - Faculdade de Letras, Universidade Federal do Rio de Janeiro, Rio de Janeiro, 2015.

FAIRCLOUGH, Norman. [1992]. Discurso e mudança social. Brasília: Editora Universidade de Brasília, 2001.

FAIRCLOUGH, Norman. Analysing discourse: textual analysis for social research. London: Routledge, 2003.

FAIRCLOUGH, Norman. [1995] Critical Discourse Analysis: the critical study of language. London: Routledge, 2010.

GILL, Rosalind. Análise de discurso. In: BAUER, Martin. W.; GASKELL, George. (Orgs.). Pesquisa qualitativa com texto, imagem e som: um manual prático. Petrópolis: Vozes, 2010. p. 244-270.

HALLIDAY, Michael. A. K.; HASAN, Ruqaiya. Language, context and text: aspects of language in a social- semiotic perspective. Oxford: Oxford University Press, 1989.

HALLIDAY, Michael. A. K.; MATTHIESSEN, Christian. M. I. M. An introduction to Functional Grammar. 3. ed. London: Routledge, 2014.

LALLI, Viviane. S. O Programa Acelera Brasil. Em Aberto, Brasília, v. 17, n. 71, 2000. Disponível em: 〈http://www.emaberto.inep.gov.br〉. Acesso em 14 jul. 2013.

LÜDKE, Menga; ANDRÉ, Marli. E.D.A. [1986] Métodos de coleta de dados: observação, entrevista e análise documental. In: LÜDKE, Menga; ANDRÉ, Marli. E.D.A. (Orgs.). Pesquisa em educação: abordagens qualitativas. Rio de Janeiro: E.P.U., 2013, p. 29 - 52.

PARRADO, Carla.; SANTOS, Simone. P. Zip from Zog, 5A: livro do aluno. Rio de Janeiro: Learning Factory, 2012a.

PARRADO, Carla.; SANTOS, Simone. P. Zip from Zog, 5A: manual do 
Zip From Zog no Acelera Brasil...

professor. Rio de Janeiro: Learning Factory, 2012b.

SÁ-SILVA, Jackson. R. et al. Pesquisa documental: pistas teóricas e metodológicas. Revista Brasileira de História \& Ciências Sociais. Ano I. Número I. Julho, 2009. Disponível em: 〈www.rbhcs.com>. Acesso em 21 out. 2012.

TILIO, Rogério; ROCHA, Cláudia. H. As dimensões da linguagem em livros didáticos de Inglês para o Ensino Fundamental I. Trabalhos em Linguística Aplicada, v. 48, n. 2, p. 295-315, 2009.

TILIO, Rogério. Linguística (Aplicada), contemporaneidade e materiais didáticos: diálogos. In: SANTOS, Leandra. I. S.; SILVA, Kleber. A. (Orgs.). Linguagem, ciência e ensino: desafios regionais e globais. Campinas: Pontes, 2013, p. 57-76.

Recebido em: 27/08/2016 Aceito em: 21/11/2016

Title: Zip From Zog in Acelera Brasil: analysing the themes on an English language teaching coursebook in a learning acceleration program 